\title{
Quantitative Analysis of Japan's Energy Security Based on Fuzzy Logic: Impact Assessment of Fukushima Accident
}

\author{
Ryohei Yamanishi, ${ }^{1}$ Yoshiyuki Takahashi, ${ }^{1,2}$ and Hironobu Unesaki ${ }^{1,2}$ \\ ${ }^{1}$ Graduate School of Energy Science, Kyoto University, Yoshida-honmachi, Sakyo-ku, Kyoto 606-8501, Japan \\ ${ }^{2}$ Research Reactor Institute, Kyoto University, Asashiro-nishi, Kumatori-cho, Sennan-gun, Osaka 590-0494, Japan \\ Correspondence should be addressed to Hironobu Unesaki; unesaki@rri.kyoto-u.ac.jp
}

Received 14 February 2017; Accepted 17 August 2017; Published 23 October 2017

Academic Editor: Guanghui Su

Copyright ( 2017 Ryohei Yamanishi et al. This is an open access article distributed under the Creative Commons Attribution License, which permits unrestricted use, distribution, and reproduction in any medium, provided the original work is properly cited.

\begin{abstract}
The Fukushima accident of March 2011 had great political, economic, and social impacts on Japan and marked a very important turning point in Japan's energy policy. As the accident has also greatly exposed the vulnerability of Japan's energy security, it is crucial to clarify the path that Japan should take to maintain and secure its energy security in case of any possible future outbreak that may threaten its energy security. For this purpose, we conducted a comprehensive and structural analysis of Japan's energy security based on APERC's 4As framework and by using fuzzy logic and the Fuzzy-DEMATEL method to quantitatively understand the performance of Japan's energy security and how the Fukushima accident had impacted the performance. Our results demonstrate that Japan's energy security has clearly degraded after experiencing Fukushima accident. In addition, the results of the structural analysis by the Fuzzy-DEMATEL method show that the most salient dimension in the 4As framework for improving Japan's energy security is the "Availability" dimension, and for this purpose nuclear energy and renewables play very important roles in securing the future energy security in Japan; this is consistent with the current energy policy measures announced in the Strategic Energy Plan of 2014
\end{abstract}

\section{Introduction}

The accident at the Fukushima Daiichi nuclear power station (Fukushima accident) that occurred in the wake of the devastating earthquake and tsunami in March 2011 has caused unprecedented catastrophic damage to life, society, and economy in Japan and become a serious event in terms of energy security. Large population was forced to move away from the affected area by the accident, and energy supply systems and infrastructures were also severely damaged. Because of the shutdown of the Fukushima nuclear power plant and subsequent closures of all other nuclear power plants across Japan, the share of nuclear power in domestic electricity supply dropped from 31.2\% in February 2011 to zero in May 2012 [1].

Fukushima accident was a significantly important event that not only revealed the vulnerability of Japan's energy security but also made us realize again the importance of energy security. After Fukushima accident, the consumption of fossil fuels, especially LNG, has greatly increased in Japan to compensate the loss of electricity supply from nuclear energy, which caused a significant increase of imported fuel cost. In fact, Japan's import payment for LNG was 5.4 trillion yen in FY2011, an increase of 52\% from FY2010. In addition, together with the increase of import payments for other fossil fuels, Japan's trade deficit had greatly expanded and reached the highest deficit of 13.8 trillion yen in FY2013 which is a substantial outflow of Japan's national wealth. The increase of imported fuel cost resulted in higher costs for power generation, and electric companies subsequently increased their power rate one after another, which severely influenced households and industries.

The increase of LNG and oil use in power generation also caused the sharp decline of energy self-sufficiency of Japan. As for LNG, imports from Qatar greatly increased in 2011, an increase of 55.4\% from the previous year, which means the Japan's import-dependence on Middle East has significantly increased $[2,3]$. It is also important to note that 
people's distrust of nuclear safety and management system greatly expanded due to Fukushima accident, which caused the general acceptability of nuclear energy to greatly decline. It can be said that the situation surrounding nuclear energy has reached the worst in Japan's history [4]. As a result of the Fukushima accident, the so-called "safety myth" surrounding nuclear energy has collapsed, and the Japanese government was forced to reconsider its energy policy and to change the institutional structure of nuclear safety regulation.

In this respect, as well as the two oil crises in the 1970s, Fukushima accident marked a very important turning point in Japan's energy policy. Therefore it is crucial to clarify the path that Japan should take to maintain and secure its energy security in case of any possible future outbreak that may threaten its energy security. For this purpose, it is essential to quantitatively analyze the impact of Fukushima accident to Japan's energy security and to clarify the factors that may serve for the improvement of future energy security.

However, several issues have been mentioned in the quantitative analysis of energy security. Energy security is a multifaceted concept, and because of its nature of ambiguity and complexity the quantification of energy security performance is not straightforward. Several evaluation methods for energy security have been suggested so far, but a concrete methodology has not been established yet [5, 6]. Many researchers have independently developed multidimensional metrics or indicators and determined an evaluation method to quantify and evaluate energy security. However, in most cases, there is a high degree of subjectivity in selecting the indicators, constructing indices, and determining weightings. Also, various factors that are impossible or hard to quantitatively evaluate have been often left out in the conventional approach toward performance evaluation of energy security based on indicators.

In order to solve these issues, fuzzy logic has recently been adopted as a method to handle nonquantitative factors and the ambiguity, but most studies using fuzzy logic for energy security analysis focus only on either a limited dimension of energy security, a particular sector, or a specific technology [7, 8]. There also have been many studies that introduced fuzzy logic to energy sector [9-12], but no comprehensive analysis of energy security using fuzzy logic has been published so far.

Another issue is the lack of structural analysis of energy security. Many studies have conducted a quantitative evaluation of energy security by using multidimensional metrics or indicators, but the mutual influences and complex interaction among the dimensions or indicators of energy security have been rarely taken into account or often been ignored [13]. Considering the complex and multifaceted characteristic of energy security, it is important for the quantitative analysis of energy security to also structurally analyze the complex interactions within the components comprising the energy security.

Based on the issues described above, this study focuses on the quantitative analysis of Japan's energy security to establish the quantitative evaluation method for comprehensive and structural analysis of energy security based on fuzzy logic and to clarify the path that Japan should take to secure its energy security in case of future outbreak of anything which may threaten Japan's energy security. The research methods adopted in this study are summarized in Section 2, where the concepts and frameworks of energy security proposed so far, the characteristics of fuzzy logic as the analysis methodology, and the reasons for choosing indicators and analytical procedure of quantitative analysis of energy security are described. Section 3 describes the results of quantitative analysis of Japan's energy security and discusses the impact of Fukushima accident on Japan's energy security as well as mutual influences among dimensions or indicators of energy security. The conclusion of this study is summarized in Section 4.

\section{Research Methods}

2.1. Concepts and Framework of Energy Security. Energy security has been one of the most important issues of any governments all over the world, particularly since the two oil crises in the 1970s. However, unlike in the 1970s when the focus of energy security was mainly on affordability and security of oil supplies, the current focus could be rather multidimensional [2]. For example, in the 21th century, as the concern related to environmental problems and social satisfactions have grown, such factors have been added to the concept of energy security. Thus, the concept and definitions of energy security have widened over time $[5,14]$. Although many studies on energy security can be found in academic publications and government reports, there is no consensus on widely accepted definition of energy security [6].

Such multidimensional aspect of energy security shows that energy security is a complex issue that a holistic approach is necessary to capture its complexity to analyze the performance of a country's energy security [15]. As the holistic approach, several conceptual frameworks of energy security have been used so far [16-18]. Among these conceptual frameworks, we use the "4As" framework introduced by the Asia Pacific Energy Research Centre [19] to quantitatively analyze Japan's energy security in this study. This framework is a frequently used framework of contemporary energy security studies as it is considered to be capable of reflecting the complexity of energy security in a broad manner [20]. The four dimensions in this framework (Availability, Accessibility, Affordability, and Acceptability) are defined in this study as follows: Availability as "having stably sufficient supplies of energy", Accessibility as "being able to have access to energy resources," Affordability as "providing energy services that are equitable, affordable for consumers," and Acceptability as "minimizing harmful influence on and being accepted by the natural environment and regional communities."

2.2. Selection of Indicators Incorporated in the 4As Framework. Table 1 presents the selected indicators composing energy security in this study. As this study aims to analyze the change of Japan's energy security after experiencing Fukushima accident and to identify the key factors for future energy security in Japan, we chose 20 indicators (five indicators in each dimension) that would be of significance for recent energy security of Japan and closely relate to nuclear energy use referring to previous studies and publications. The detailed 
TABLE 1: Selected indicators of energy security.

\begin{tabular}{lc}
\hline Dimension & Indicator \\
\hline Availability & $\begin{array}{c}\text { Self-sufficiency (AV1) } \\
\text { Oil stock (AV2) }\end{array}$ \\
& $\begin{array}{c}\text { TPES (AV4) } \\
\text { Share of renewables in total electricity supply (AV3) } \\
\text { Total installed electricity generation capacity (AV5) }\end{array}$ \\
Accessibility & $\begin{array}{c}\text { Dependency on Middle East oil (AS1) } \\
\text { The effort to promote renewable energies (AS2) }\end{array}$ \\
& $\begin{array}{c}\text { The effort to promote independently developed energy resources (AS3) } \\
\text { Human resources for nuclear energy (AS4) }\end{array}$ \\
The difficulty in operating nuclear power station (AS5)
\end{tabular}

discussion on individual indicators is given in the following sections. Indicators that cannot always be quantified by certain metrics were also included; these factors have been often ignored in previous energy security studies due to their difficulty of quantification, but they are considered to be crucial in this study to describe the complexity and ambiguity of energy security and will be handled using the fuzzy logic as described in Section 2.3.

2.2.1. Availability Indicators. In this study, the "Availability" dimension consists of following indicators that relate to the ability of a country to supply enough energy to meet its domestic energy demand.

(i) Self-sufficiency (AV1): this indicator represents energy that can be secured inside a country of total consumed primary energy in a country and reflects the resilience to the interruption of imported energy.

(ii) Oil stock (AV2): this indicator measures the oil stock secured in preparation for sudden fluctuation of energy supply and demand caused by energy crises such as the oil crises and greatly reflects the rapid change in energy situation.

(iii) Share of renewables in total electricity supply (AV3): this indicator reflects the diversity of energy sources used for energy supply. Especially in a resource poor country such as Japan, it is a very important factor for the Availability dimension.

(iv) TPES (AV4): this indicator measures the necessary primary energy in meeting national energy demand and may reflect the energy reduction or the energy efficiency. (v) Total electricity generation capacity (AV5): this indicator reflects the adequacy of electricity generation capacity in meeting national electricity demand.

2.2.2. Accessibility Indicators. The "Accessibility" dimension refers to indicators that relate to the ability of a country to secure energy sources both inside and outside country.

(i) Dependency on Middle East oil (AS1): this indicator is commonly used to measure the security level of a country's energy supply. Especially in Japan, this have been one of the most important factors concerning energy security.

(ii) The effort to promote renewable energies (AS2): this indicator reflects the degree to which a country makes efforts to introduce renewable energies.

(iii) The effort to promote independently developed energy resources (AS3): this indicator reflects the degree to which a country makes efforts to develop nonconventional resources and acquires interests of Japanese companies in foreign fields of energy resources.

(iv) Human resources for nuclear energy (AS4): this indicator represents the human resource development and the number of human resources that are necessary for continuous development of nuclear industries. The issues about human resources for nuclear energy have been concerned since Fukushima accident; therefore this indicator is considered to be important for the Accessibility dimension. 
(v) The difficulty in operating nuclear power station (AS5): this indicator can be measured by the several obstacles that a country or an electric company must overcome to operate a nuclear power station. It can be said that this indicator is the most closely related to nuclear energy use; therefore it is essential for the Accessibility dimension.

2.2.3. Affordability Indicators. The "Affordability" dimension consists of the following indicators that relate to energy prices for households and industries and reflect the economic activities and the energy situations in Japan.

(i) Fuel cost of electric companies (AF1): this indicator represents the degree to which it costs electric companies to import fuels for electricity generation and reflects the dependency on imported fuels.

(ii) Electricity price (AF2): this indicator reflects the burden on households and industries to use electricity.

(iii) Market price of LNG (AF3): this indicator reflects the change of the energy situation in global market of LNG. Especially in Japan, where most of LNG are imported from foreign countries, it directly influences the Japanese economy.

(iv) Trade balance (AF4): this indicator reflects the economic condition and the energy situation of Japan, which is directly influenced by energy trade.

(v) Economic growth ratio (AF5): this indicator reflects the condition of domestic economic activities, which is influenced by the change of the energy situation.

2.2.4. Acceptability Indicators. In this study, the "Acceptability" dimension consists of indicators that relate to the environmental and social concern resulted from energy production and consumption.

(i) Consumption of fossil fuels (AP1): this indicator directly relates to $\mathrm{CO} 2$ emission, which negatively affects the global environment, and also reflects the energy mix in a given country.

(ii) $\mathrm{CO} 2$ emission from energy sources (AP2): this indicator is commonly used to measure the global environmental impact resulted from energy use; therefore it is an essential factor in the Acceptability dimension.

(iii) Radioactive waste (AP3): this indicator reflects the degree to which a country makes efforts to dispose radioactive wastes without negatively affecting the natural environment and human health. The circumstances surrounding the radioactive waste disposal have been greatly influenced by Fukushima accident; therefore this indicator is essential for the Acceptability dimension.

(iv) Supporting ratio for nuclear energy (AP4): this indicator reflects public opinions or attitudes toward nuclear energy. After Fukushima accident, this is considered to be one of the most important indicators concerning the Acceptability dimension in Japan.

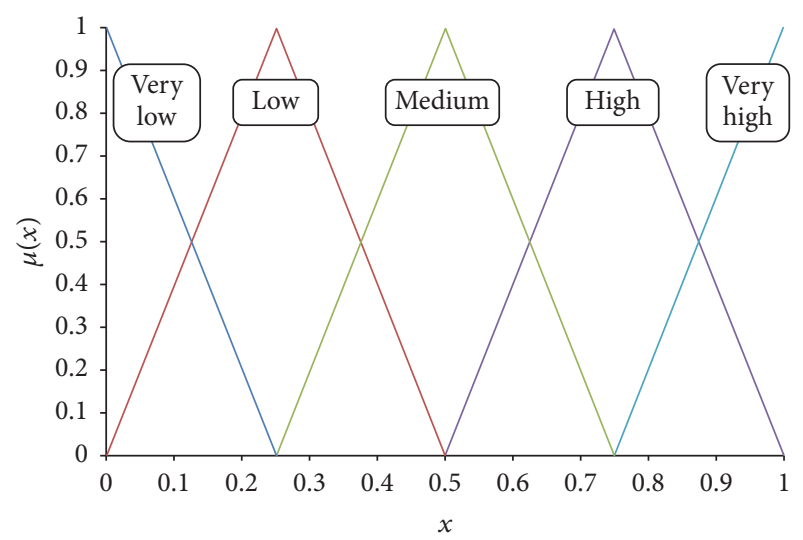

FIGURE 1: Membership functions for linguistic values in fuzzy reasoning.

(v) Voice and accountability (AP5): this indicator is one of the World Governance Indicators [21] and in this study reflects the degree to which a country's citizens are able to participate in the government and the government fulfills its accountability.

\subsection{Analytical Procedure}

2.3.1. Fuzzy Logic as a Tool for Energy Security Evaluation. Fuzzy logic, which was first proposed and established by Zadeh [22, 23], is a powerful tool to quantitatively analyze and evaluate various types of problems including the ambiguity such as human activities or perceptions. Fuzzy logic could be considered as a departure from classical two-valued sets and logic (e.g., "true" or "false") and uses "soft" linguistic (e.g., "large," "hot," and "tall") system variables and a continuous range of truth values in the interval $[0,1]$, rather than strict binary decisions and assignments [9]. We have adopted the fuzzy logic analysis to quantitative evaluation of energy security in this study to express the ambiguity included in the indicators or weightings by using linguistic values and to evaluate factors that are difficult to be quantified.

2.3.2. Quantitative Analysis of Japan's Energy Security before and after Fukushima Accident. In order to quantitatively analyze the change of Japan's energy security after experiencing Fukushima accident, the time window for the analysis of Japan's energy security performance was determined to be from FY2008 to FY2013. 12 linguistic values (fuzzy numbers) that are defined by the membership functions were used for fuzzy logic analysis. These linguistic values are expressed by main five linguistic values (Very Low (VL), Low (L), Medium (M), High (H), and Very High (VH)) as shown in Figure 1. Table 2 represents the 12 linguistic values used for measuring Japan's energy security in this study. Membership functions can be described in several manners such as triangle, trapezoid, or Gaussian distribution, but as it has been reported that the difference of shape of membership function can hardly influence the final result [24], the triangular membership function is adopted in this study. 
TABLE 2: 12 linguistic values for fuzzy reasoning.

\begin{tabular}{lc}
\hline Linguistic value & Abbr. \\
\hline Very Low & VL \\
Very Low or Low & VL or L \\
Low & L \\
Low or Medium & L or M \\
Medium & $\mathrm{M}$ \\
Medium or High & $\mathrm{M}$ or H \\
High & $\mathrm{H}$ \\
High or Very High & $\mathrm{H}$ or VH \\
Very High & $\mathrm{VH}$ \\
Very Low or Low or Medium (= not High) & VL or L or M \\
Low or Medium or High & $\mathrm{L}$ or M or H \\
Medium or High of Very High $(=$ not Low $)$ & $\mathrm{M}$ or H or VH \\
\hline
\end{tabular}

First, we subjectively evaluated each indicator by using 12 linguistic values based on quantitative data and qualitative analysis as summarized in Table 3. In this study, for simplicity, weightings of each indicator are treated as equal.

Then, we quantified each dimension of $4 \mathrm{As}$ framework based on the principle of fuzzy reasoning. The methodology for the quantification is based on the studies of nuclear fuel cycle proliferation resistance evaluation by using fuzzy logic $[24,25]$ and will be described briefly as follows.

Fuzzy numbers of each indicator are combined to obtain a fuzzy number of a given dimension $\widetilde{F}=\left\{x_{\widetilde{F}_{s}} \mid \mu_{\widetilde{F}_{s}}\left(x_{\widetilde{F}_{s}}\right)\right\}$ for a given year $s$. Calculation of $\widetilde{F}$ is based on the following:

$$
\begin{gathered}
x_{\widetilde{F}_{s}}=\frac{\sum_{k=1}^{N} x_{\widetilde{A}_{s k}} w_{k}}{\sum_{k=1}^{N} w_{k}}, \\
\mu_{\widetilde{F}_{s}}\left(x_{\widetilde{F}_{s}}\right)=\max _{{\widetilde{A}}_{s k}}\left(\min \left(\mu_{\widetilde{A}_{s k}}\left(x_{\widetilde{A}_{s k}}\right)\right),\right.
\end{gathered}
$$

where $\widetilde{A}_{s k}$ is the fuzzy number of the indicator $k$ for the year $s, \widetilde{w}_{k}$ is the weighting of the indicator $k$ for a given dimension (in this study $\widetilde{w}_{k}=1$ ), and $\mu_{\widetilde{A}_{s k}}\left(x_{\widetilde{A}_{s k}}\right)$ is the membership function of each indicator.

The calculation process to combine fuzzy numbers of indicators uses the following procedures based on random sampling technique;

Step 1 (initialization). Assign $\mu_{\widetilde{F}_{s}}\left(x_{\widetilde{F}_{s}}\right)=0$ for $0 \leq x_{\widetilde{F}_{s}} \leq 1$.

Step 2. Randomly pick up groups $x_{\widetilde{A}_{s k}}$ and $\mu_{\widetilde{A}_{s k}}\left(x_{\widetilde{A}_{s k}}\right)$ for all indicators $(k=1,2, \ldots, N)$; then calculate the membership function of this group based on (3) and $x_{\widetilde{F}}$ for $\mu$ (group) based on (1) (minimum membership is used because the logical relationship of the effectiveness among all indicators within each dimension is an "AND" operation):

$$
\mu(\text { group })=\min \left(\mu_{\widetilde{A}_{s k}}\left(x_{\widetilde{A}_{s k}}\right)\right), \quad k=1,2, \ldots, N .
$$

Step 3. Using $\mu$ (group) calculated in Step 2 , set $\mu_{\widetilde{F}_{s}}\left(x_{\widetilde{F}_{s}}\right)$ based on (4) (maximum membership is used because the logical relationship of the indicator effectiveness among all groups reaching point $x_{\widetilde{F}_{s}}$ among the collected samples is an "OR" operation):

$$
\mu_{\widetilde{F}_{s}}\left(x_{\widetilde{F}_{s}}\right)=\max _{x_{\widetilde{F}_{s}}}(\mu(\text { group })) .
$$

Step 4. Repeat Steps 1 to 3 until the range of $x_{\widetilde{A}_{s k}}$ is fully covered.

Step 5. Defuzzify the fuzzy result using (5) of a given dimension. This function yields the centroid value of a fuzzy number and is called a crisp value of a fuzzy number:

$$
\text { crisp value }=\frac{\sum \mu_{A}(x) x}{\sum \mu_{A}(x)} .
$$

The energy security index for a given dimension is defined as this crisp value.

Step 6. Integrate crisp values of all four dimensions to obtain the overall energy security index.

2.3.3. Structural Analysis of Japan's Energy Security. In order to identify the key factors for Japan's energy security, we conducted the structural analysis of energy security by utilizing the Fuzzy-DEMATEL (Fuzzy Decision-Making Trial Evaluation Laboratory) method. The DEMATEL method, which was first introduced by The Battelle Memorial Institute through its Geneva Research Centre in 1973 [26], is a method for building and analyzing a structural model for understanding the cause-effect relationship among complex criteria by visualizing the complicated structure of a system and separating the criteria into the cause and effect group. The DEMATEL method is useful to quantitatively analyze the direct influences among factors composing in problem and their strengths in the problem where the components and their relationships are so complex and unclear that the problem is impossible to analyze in a conventional manner. The Fuzzy-DEMATEL method combines fuzzy logic and the DEMATEL method to take into consideration the vagueness of human decision or judgement in the problem [27]. There are numbers of studies utilizing the Fuzzy-DEMATEL method for a wide variety of system analyses [28-31], but there is very limited study published on structural analysis of energy security [13]. In this study, the Fuzzy-DEMATEL method is adopted to quantitatively identify the cause-effect relationships among dimensions and indicators of Japan's energy security to determine the energy security strategies.

The Fuzzy-DEMATEL analysis was performed for among four dimensions of 4 As (Case 1), among five indicators in each dimension (Case 2), and among all indicators in energy security (Case 3). Direct-influenced relationships among factors were evaluated by using five linguistic values, which consist of "No influence" (N), "Very Low influence" (VL), "Low influence" (L), "High influence" (H), and "Very High influence" (VH) defined by the membership functions shown in Figure 2. Table 4 represents five linguistic values used for the Fuzzy-DEMATEL analysis in this study.

First, we subjectively evaluated the direct-influenced relationships among the factors by using five linguistic values 
TABLE 3: Evaluation of each indicator by 12 linguistic values.

\begin{tabular}{|c|c|c|c|c|c|c|c|}
\hline Dimension & Indicator & 2008 & 2009 & 2010 & 2011 & 2012 & 2013 \\
\hline \multirow{5}{*}{ Availability } & AV1 & $\mathrm{H}$ or $\mathrm{VH}$ & $\mathrm{H}$ or $\mathrm{VH}$ & $\mathrm{H}$ or $\mathrm{VH}$ & $\mathrm{L}$ & $\mathrm{VL}$ & $\mathrm{VL}$ \\
\hline & AV2 & VH & VH & $\mathrm{H}$ or $\mathrm{VH}$ & $\mathrm{M}$ or $\mathrm{H}$ or $\mathrm{VH}$ & $\mathrm{VH}$ & $\mathrm{VH}$ \\
\hline & AV3 & VL or $\mathrm{L}$ & VL or L & VL or L & $\mathrm{VL}$ or $\mathrm{L}$ or $\mathrm{M}$ & VL or $\mathrm{L}$ or $\mathrm{M}$ & $\mathrm{VL}$ or $\mathrm{L}$ or $\mathrm{M}$ \\
\hline & AV4 & L & $\mathrm{L}$ or $\mathrm{M}$ or $\mathrm{H}$ & L & $\mathrm{H}$ or $\mathrm{VH}$ & $\mathrm{VH}$ & $\mathrm{H}$ or $\mathrm{VH}$ \\
\hline & AV5 & $\mathrm{H}$ or $\mathrm{VH}$ & $\mathrm{H}$ or $\mathrm{VH}$ & $\mathrm{H}$ or $\mathrm{VH}$ & $\mathrm{H}$ & $\mathrm{H}$ & $\mathrm{H}$ \\
\hline \multirow{5}{*}{ Accessibility } & AS1 & $\mathrm{VL}$ & $\mathrm{VL}$ & $\mathrm{VL}$ & $\mathrm{VL}$ & VL or $\mathrm{L}$ & VL or $\mathrm{L}$ \\
\hline & AS2 & $\mathrm{H}$ or $\mathrm{VH}$ & $\mathrm{H}$ or $\mathrm{VH}$ & $\mathrm{H}$ or $\mathrm{VH}$ & $\mathrm{H}$ or $\mathrm{VH}$ & VH & VH \\
\hline & AS3 & $\mathrm{L}$ or $\mathrm{M}$ or $\mathrm{H}$ & $\mathrm{M}$ or $\mathrm{H}$ & $\mathrm{M}$ or $\mathrm{H}$ & $\mathrm{M}$ or $\mathrm{H}$ & $\mathrm{H}$ or $\mathrm{VH}$ & $\mathrm{H}$ or $\mathrm{VH}$ \\
\hline & AS4 & $\mathrm{VH}$ & VH & VH & $\mathrm{M}$ or $\mathrm{H}$ or $\mathrm{VH}$ & $\mathrm{M}$ or $\mathrm{H}$ or $\mathrm{VH}$ & $\mathrm{M}$ or $\mathrm{H}$ or $\mathrm{VH}$ \\
\hline & AS5 & $\mathrm{VH}$ & $\mathrm{VH}$ & $\mathrm{VH}$ & L or $\mathrm{M}$ & L or $\mathrm{M}$ & VL \\
\hline \multirow{5}{*}{ Affordability } & AF1 & VL or $\mathrm{L}$ & VL or $\mathrm{L}$ or $\mathrm{M}$ & VL or $\mathrm{L}$ or $\mathrm{M}$ & VL or $\mathrm{L}$ & $\mathrm{VL}$ & $\mathrm{VL}$ \\
\hline & AF2 & $\mathrm{L}$ or $\mathrm{M}$ & $\mathrm{L}$ or $\mathrm{M}$ or $\mathrm{H}$ & $\mathrm{L}$ or $\mathrm{M}$ or $\mathrm{H}$ & $\mathrm{L}$ or $\mathrm{M}$ or $\mathrm{H}$ & $\mathrm{L}$ & $\mathrm{L}$ \\
\hline & AF3 & VL & VL or L & VL or L & VL & VL & VL \\
\hline & AF4 & $\mathrm{L}$ or $\mathrm{M}$ & $\mathrm{H}$ & $\mathrm{H}$ & $\mathrm{L}$ & VL & VL \\
\hline & AF5 & VL & VL & $\mathrm{VH}$ & VL or $\mathrm{L}$ or $\mathrm{M}$ & M & $\mathrm{H}$ or $\mathrm{VH}$ \\
\hline \multirow{5}{*}{ Acceptability } & AP1 & $\mathrm{VL}$ & VL or $\mathrm{L}$ & $\mathrm{VL}$ & $\mathrm{VL}$ & $\mathrm{VL}$ & $\mathrm{VL}$ \\
\hline & AP2 & VL or L & $\mathrm{L}$ or $\mathrm{M}$ & VL or L & VL & VL & VL \\
\hline & AP3 & $\mathrm{L}$ or $\mathrm{M}$ or $\mathrm{H}$ & $\mathrm{L}$ or $\mathrm{M}$ or $\mathrm{H}$ & $\mathrm{L}$ or $\mathrm{M}$ or $\mathrm{H}$ & VL or $\mathrm{L}$ & VL or L & VL \\
\hline & AP4 & $\mathrm{H}$ or $\mathrm{VH}$ & $\mathrm{H}$ or $\mathrm{VH}$ & $\mathrm{H}$ or $\mathrm{VH}$ & VL & VL & VL \\
\hline & AP5 & VL or L & VL or L & VL or L & VL or L & $\mathrm{L}$ or $\mathrm{M}$ or $\mathrm{H}$ & $\mathrm{L}$ or $\mathrm{M}$ or $\mathrm{H}$ \\
\hline
\end{tabular}

TABle 4: The fuzzy linguistic scale for the Fuzzy-DEMATEL analysis.

\begin{tabular}{lcc}
\hline Linguistic values & Abbr. & Triangular fuzzy numbers \\
\hline No influence & $\mathrm{N}$ & $(0,0,0.25)$ \\
Very Low influence & $\mathrm{VL}$ & $(0,0.25,0.50)$ \\
Low influence & $\mathrm{L}$ & $(0.25,0.50,0.75)$ \\
High influence & $\mathrm{H}$ & $(0.50,0.75,1.00)$ \\
Very High influence & $\mathrm{VH}$ & $(0.75,1.00,1.00)$ \\
\hline
\end{tabular}

TABLE 5: Direct-influenced relation matrix using linguistic values for 4As (Case 1).

\begin{tabular}{lcccc}
\hline 4As & AV & AS & AF & AP \\
\hline Availability (AV) & N & H & VH & VH \\
Accessibility (AS) & VH & N & H & L \\
Affordability (AF) & H & L & N & H \\
Acceptability (AP) & L & H & L & N \\
\hline
\end{tabular}

based on quantitative data and qualitative analysis. The results of linguistic value assignments are shown in Tables 5-9. The direct-influenced relation matrix for Case 3 (among all indicators of energy security) will not be represented for simplicity. The Fuzzy-DEMATEL analysis is performed using the procedures described in Appendix.

\section{Results and Discussions}

3.1. Japan's Energy Security before and after Fukushima Accident. The result of energy security index of overall energy security and each dimension of 4As from FY2008 to FY2013

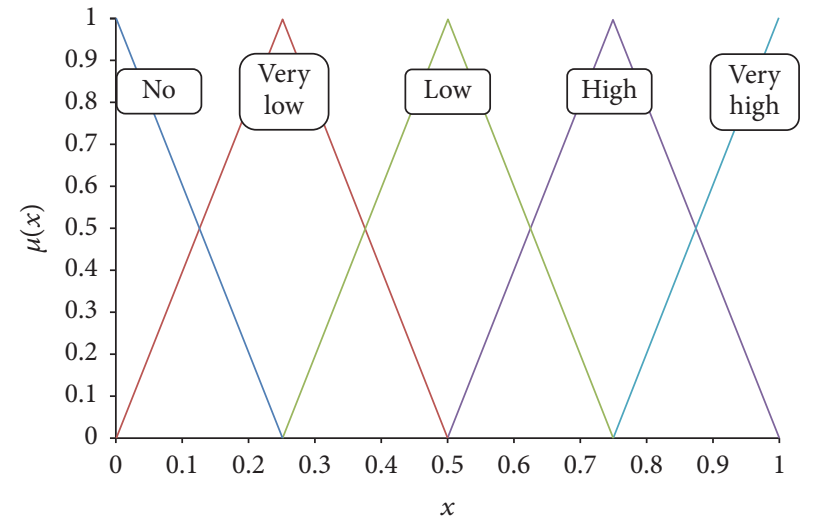

Figure 2: Membership functions for linguistic values in FuzzyDEMATEL analysis.

is shown in Figures 3 and 4, respectively. Until the Fukushima accident in 2011, a gentle upward trend in Japan's energy security is observed, but after 2011 the energy security clearly turned to decline. The energy security index dropped in 2011, down 25\% from the previous year, suggesting that Fukushima accident negatively affected Japan's energy security. In 2013, slight improvement of energy security could be observed, but it still remains below the level before Fukushima accident. It is likely that this upward trend after 2012 has resulted from the change of government's measures to deal with Fukushima accident; immediately after the accident, the Japanese government took short-term measures such as electricity saving or carrying out planned blackouts to cope with the sudden disruption of electricity supply. However, 
TABLE 6: Direct-influenced relation matrix using linguistic values for Availability (Case 2).

\begin{tabular}{|c|c|c|c|c|c|}
\hline Availability & AV1 & AV2 & AV3 & AV4 & AV5 \\
\hline Self-sufficiency (AV1) & $\mathrm{N}$ & $\mathrm{N}$ & $\mathrm{N}$ & $\mathrm{N}$ & $\mathrm{N}$ \\
\hline Oil stock (AV2) & $\mathrm{H}$ & $\mathrm{N}$ & $\mathrm{N}$ & $\mathrm{N}$ & $\mathrm{N}$ \\
\hline Share of renewables in total electricity supply (AV3) & $\mathrm{VH}$ & VL & $\mathrm{N}$ & $\mathrm{VH}$ & $\mathrm{N}$ \\
\hline TPES (AV4) & $\mathrm{VH}$ & $\mathrm{L}$ & $\mathrm{H}$ & $\mathrm{N}$ & $\mathrm{L}$ \\
\hline Total installed electricity generation capacity (AV5) & $\mathrm{H}$ & $\mathrm{N}$ & $\mathrm{VH}$ & $\mathrm{N}$ & $\mathrm{N}$ \\
\hline
\end{tabular}

TABLE 7: Direct-influenced relation matrix using linguistic values for Accessibility (Case 2).

\begin{tabular}{lccccc}
\hline Accessibility & AS1 & AS2 & AS3 & AS4 & AS5 \\
\hline Dependency on Middle East oil (AS1) & $\mathrm{N}$ & $\mathrm{H}$ & $\mathrm{VH}$ & $\mathrm{N}$ & $\mathrm{N}$ \\
The effort to promote renewable energies (AS2) & $\mathrm{H}$ & $\mathrm{N}$ & $\mathrm{N}$ & $\mathrm{VL}$ & $\mathrm{N}$ \\
The effort to promote independently developed energy resources (AS3) & $\mathrm{VH}$ & $\mathrm{N}$ & $\mathrm{N}$ & $\mathrm{N}$ & $\mathrm{N}$ \\
Human resources for nuclear energy (AS4) & $\mathrm{N}$ & $\mathrm{N}$ & $\mathrm{N}$ & $\mathrm{N}$ & VH \\
The difficulty in operating nuclear power station (AS5) & $\mathrm{H}$ & $\mathrm{H}$ & $\mathrm{VL}$ & $\mathrm{VH}$ & $\mathrm{N}$ \\
\hline
\end{tabular}

TABLE 8: Direct-influenced relation matrix using linguistic values for Affordability (Case 2).

\begin{tabular}{lccccc}
\hline Affordability & AF1 & AF2 & AF3 & AF4 & AF5 \\
\hline Fuel cost of electric companies (AF1) & N & H & N & VH & N \\
Electricity price (AF2) & N & N & N & N & H \\
Market price of LNG (AF3) & VH & H & N & H & N \\
Trade balance (AF4) & N & N & N & N & VL \\
Economic growth ratio (AF5) & H & N & VL & H & N \\
\hline
\end{tabular}

TABLE 9: Direct-influenced relation matrix using linguistic values for Acceptability (Case 2).

\begin{tabular}{lccccc}
\hline Acceptability & AP1 & AP2 & AP3 & AP4 & AP5 \\
\hline Consumption of fossil fuels (AP1) & N & VH & N & L & N \\
CO2 emission from energy sources (AP2) & N & N & N & H & VL \\
Radioactive waste (AP3) & H & N & N & VH & VH \\
Supporting ratio for nuclear energy (AP4) & N & N & VH & N & H \\
Voice and accountability (AP5) & N & N & VH & VH & N \\
\hline
\end{tabular}

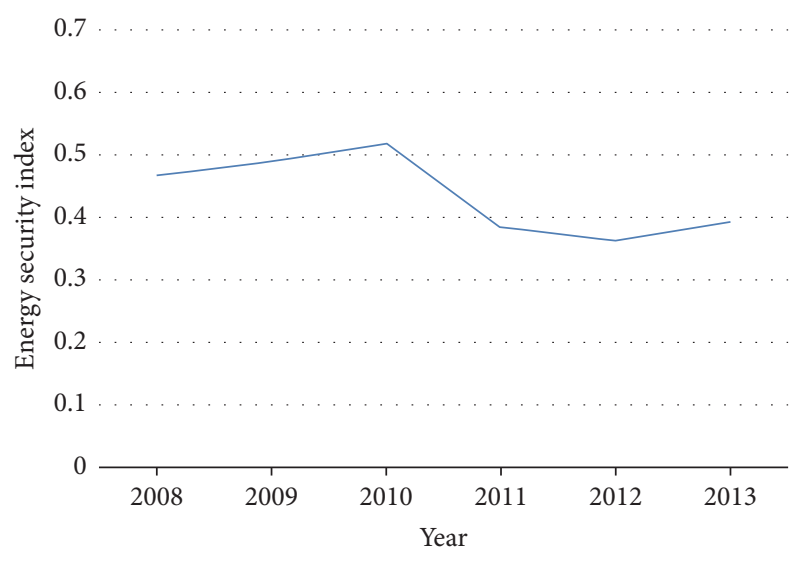

FIGURE 3: Japan's energy security from 2008 to 2013.

since 2012, when social dislocation caused by Fukushima accident gradually began to recover, the government has been able to take medium- or long-term measures such as establishment of relevant institutions and enhancement of regulations to secure and improve energy security. Therefore, it can be said that Japan's effort after Fukushima accident to secure energy security has been successful to a certain extent.

In respect to each dimension of $4 \mathrm{As}$, it is found that the each dimension has changed in different manners as shown in Figure 4. In the Availability dimension, there are almost no fluctuations. The ratio of self-sufficiency (AV1) greatly dropped due to the consecutive shutdown of nuclear power plants, whereas other indicators such as share of renewables in total electricity supply (AV3) or TPES (AV4) have improved. Therefore as a whole, the Availability dimension has not greatly changed after Fukushima accident, which indicates that although Fukushima accident caused the concern over supply disruption after the nuclear accident, it had not seriously affected Japan's energy security in terms of energy availability. In the Accessibility dimension, there are also no significant changes before and after Fukushima accident. Immediately after Fukushima accident the level of 


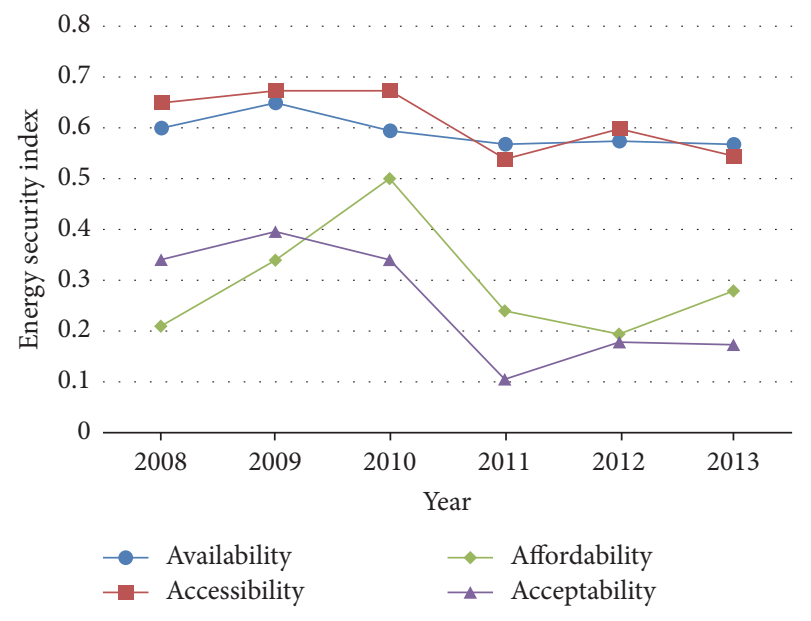

FIGURE 4: Each dimension of 4As from 2008 to 2013.

Accessibility temporarily dropped, but it recovered in 2012 . This is due to the government's actions toward establishment of relevant institutions and enhancement of regulations which aimed to improve energy use or access, and it can be said that from this result the government's effort to secure energy security was successful.

On the other hand, in contrast with the aforementioned dimensions, the Affordability and Acceptability dimensions declined significantly after Fukushima accident, which implies that the change of Japan's energy structure caused by the stoppage of nuclear power plants had a significant impact on both dimensions. After Fukushima accident, share of nuclear energy in primary energy supply has greatly decreased and subsequently the consumption of fossil fuels has increased, which caused a serious impact on costs for energy use, environmental concerns, and economic activities. These results indicate that Fukushima accident had much bigger impacts on economic, environmental, and social aspects than on aspects of supply stability of energy and access to energy sources.

3.2. Structural Analysis of Japan's Energy Security. The results of structural analysis of energy security by the FuzzyDEMATEL method are shown in Tables 10-15. Here, the total-influenced relation matrix includes both direct and indirect effects among factors. The cause-effect relationship diagram is given by mapping the dataset $(D+R, D-R)$ as shown in Figures 5-10. In these diagrams, the horizontal axis, $D+R$, represents the importance of the indicators, whereas the vertical axis, $D-R$, represents the influence of the indicators; the upper half domain (positive $D-R$ ) is called the cause group and the lower half domain (negative $D-R$ ) is called the effect group. The grouping of indicators into cause/effect group in the studied system based on the cause-effect relationship diagram is effective in finding out the components which are more influential to the system.

3.2.1. Structural Analysis of Four Dimensions of 4As (Case 1). Table 10 and Figure 5 show the result of Fuzzy-DEMATEL

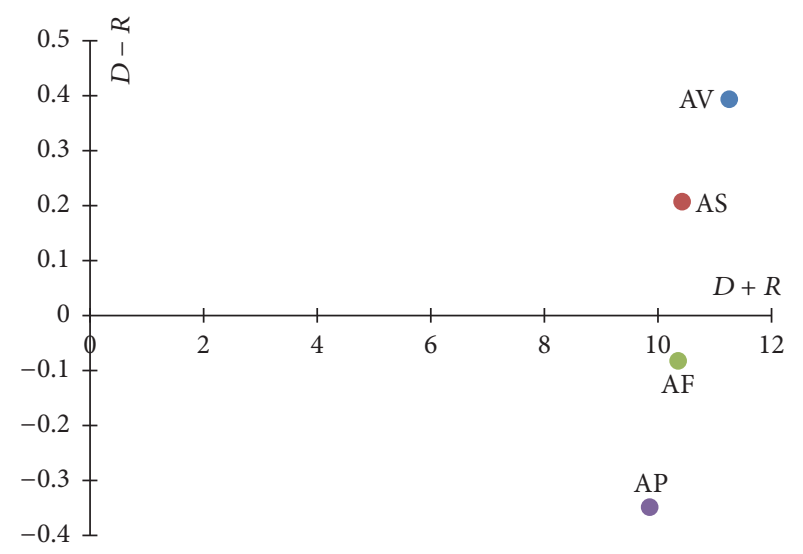

FIGURE 5: Cause-effect relationship diagram for 4As (Case 1). AV: Availability; AS: Accessibility; AF: Affordability; AP: Acceptability.

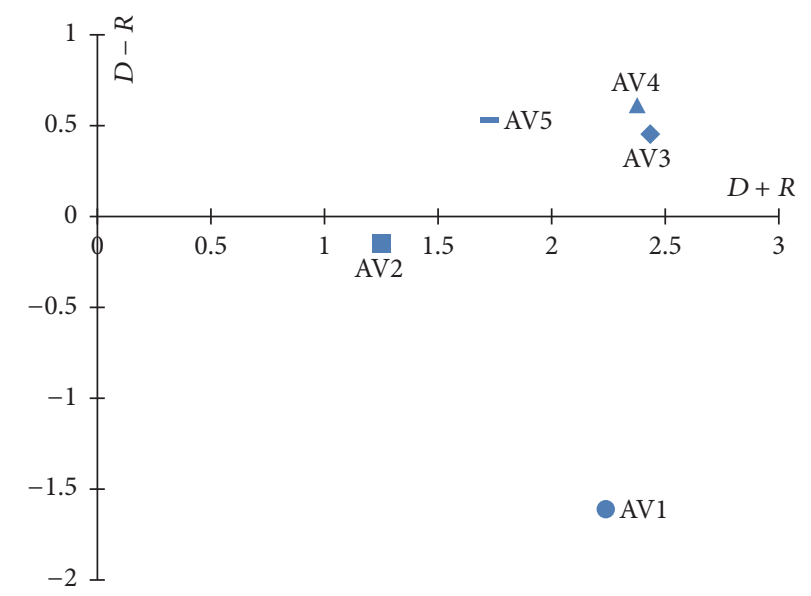

FIGURE 6: Cause-effect relationship diagram for Availability (Case 2).

analysis for 4As of energy security. The Availability and Accessibility dimensions are categorized as a cause group according to positive values of $D-R$, and the Affordability and Acceptability dimensions are categorized as an effect group according to the negative value of $D-R$. The values of $R$ (the degree to which the factor is influenced by other factors) are of the same degree in four dimensions, but, as for the value of $D$ (the degree to which the factor influences other factors), the Availability dimension shows the highest value. Both the importance $(D+R)$ and influence $(D-R)$ values of the Availability dimension are also the highest of four dimensions. It is true that although, to varying degree, all dimensions of 4 As has mutual influence, it is necessary to establish a comprehensive energy strategy which could cover all dimensions for the improvement of overall energy security. However, our results suggest that the reinforcement of the Availability dimension is the most effective measure to secure and improve Japan's energy security.

3.2.2. Structural Analysis of Five Indicators of Each Dimension (Case 2). The results of the structural analysis of the indicators of each dimension of energy security are shown in 
TABLE 10: The result of Fuzzy-DEMATEL analysis for 4As (Case 1).

\begin{tabular}{lcccccccc}
\hline \multirow{2}{*}{ Dimension } & \multirow{2}{*}{$\mathrm{N}$} & \multirow{2}{*}{$\mathrm{N}$} & \multirow{2}{*}{$\mathrm{N}+\mathrm{R}$} & \multirow{2}{*}{$D-R$} & \multicolumn{4}{c}{ Total-influenced relation matrix } \\
& & & & & AV & AS & AF & AP \\
\hline Availability (AV) & 4.17 & 3.74 & 11.24 & 0.39 & 0.895 & 1.042 & 1.114 & 1.119 \\
Accessibility (AS) & 3.82 & 3.59 & 10.41 & 0.21 & 1.049 & 0.798 & 1.012 & 0.961 \\
Affordability (AF) & 3.61 & 3.74 & 10.33 & -0.08 & 0.964 & 0.893 & 0.788 & 0.974 \\
Acceptability (AP) & 3.32 & 3.76 & 9.85 & -0.35 & 0.858 & 0.888 & 0.856 \\
\hline
\end{tabular}

TABLE 11: The result of Fuzzy-DEMATEL analysis for Availability (Case 2).

\begin{tabular}{|c|c|c|c|c|c|c|c|c|c|}
\hline \multirow{2}{*}{ Indicator } & \multirow{2}{*}{$D$} & \multirow{2}{*}{$R$} & \multirow{2}{*}{$D+R$} & \multirow{2}{*}{$D-R$} & \multicolumn{5}{|c|}{ Total-influenced relation matrix } \\
\hline & & & & & AV1 & AV2 & AV3 & AV4 & AV5 \\
\hline Self-sufficiency (AV1) & 0.22 & 1.94 & 2.23 & -1.60 & 0.056 & 0.035 & 0.031 & 0.035 & 0.031 \\
\hline Oil stock (AV2) & 0.55 & 0.71 & 1.25 & -0.15 & 0.328 & 0.048 & 0.042 & 0.047 & 0.043 \\
\hline Share of renewables in total electricity supply (AV3) & 1.48 & 0.98 & 2.44 & 0.45 & 0.577 & 0.221 & 0.159 & 0.417 & 0.129 \\
\hline TPES (AV4) & 1.53 & 0.86 & 2.38 & 0.61 & 0.576 & 0.266 & 0.306 & 0.156 & 0.242 \\
\hline Total installed electricity generation capacity (AV5) & 1.17 & 0.54 & 1.72 & 0.53 & 0.407 & 0.104 & 0.392 & 0.170 & 0.069 \\
\hline
\end{tabular}

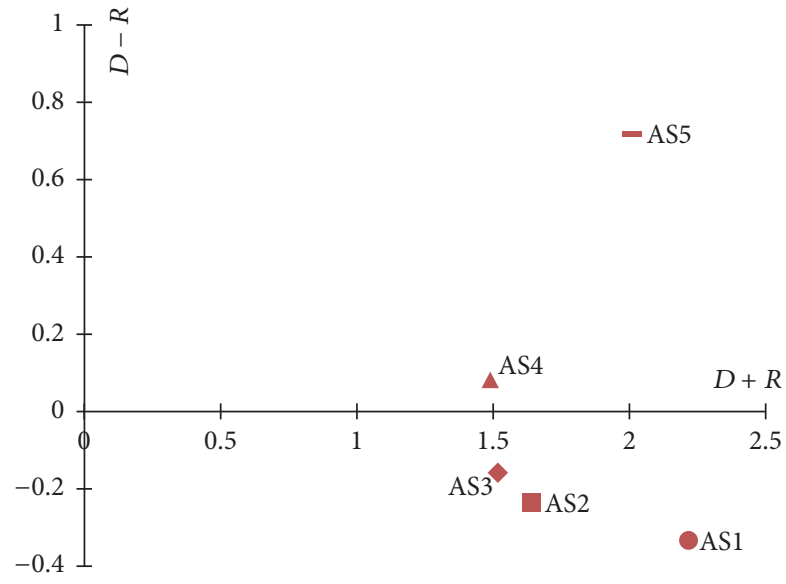

FIgURE 7: Cause-effect relationship diagram for Accessibility (Case 2).

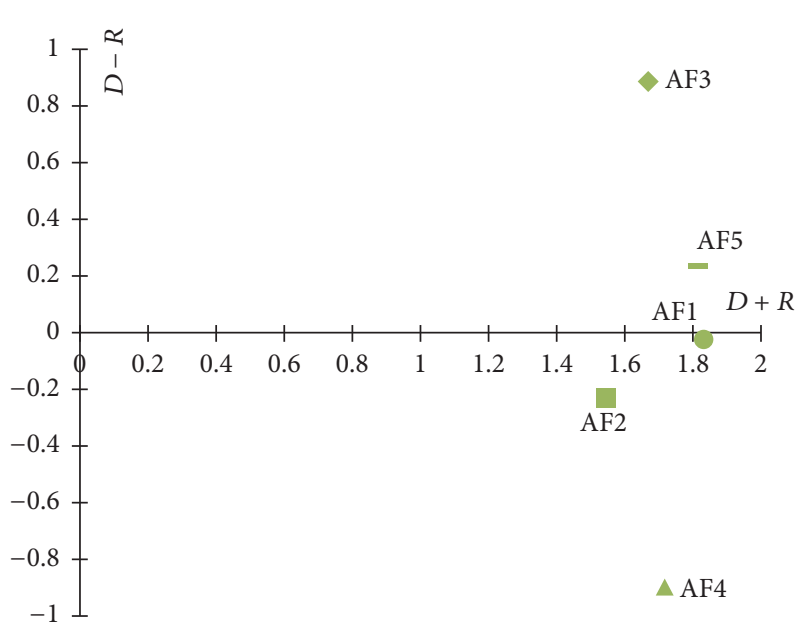

Figure 8: Cause-effect relationship diagram for Affordability (Case 2).

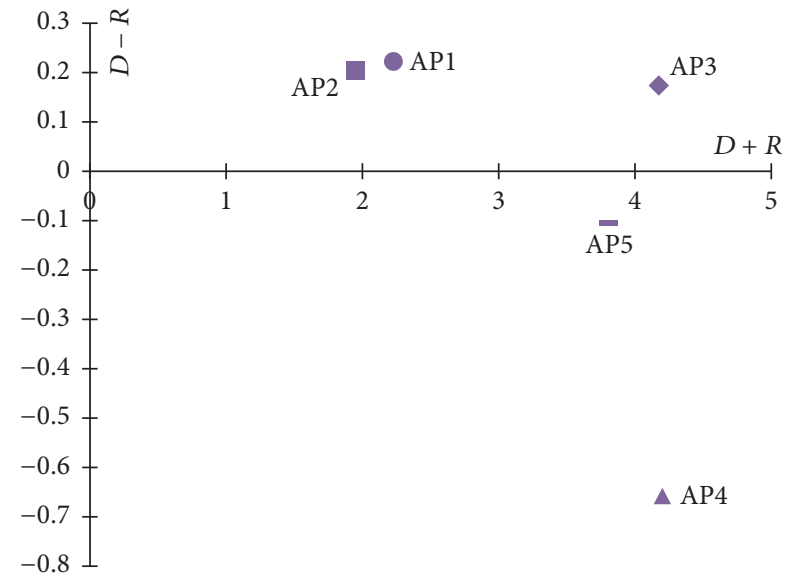

FIgURE 9: Cause-effect relationship diagram for Acceptability (Case 2).

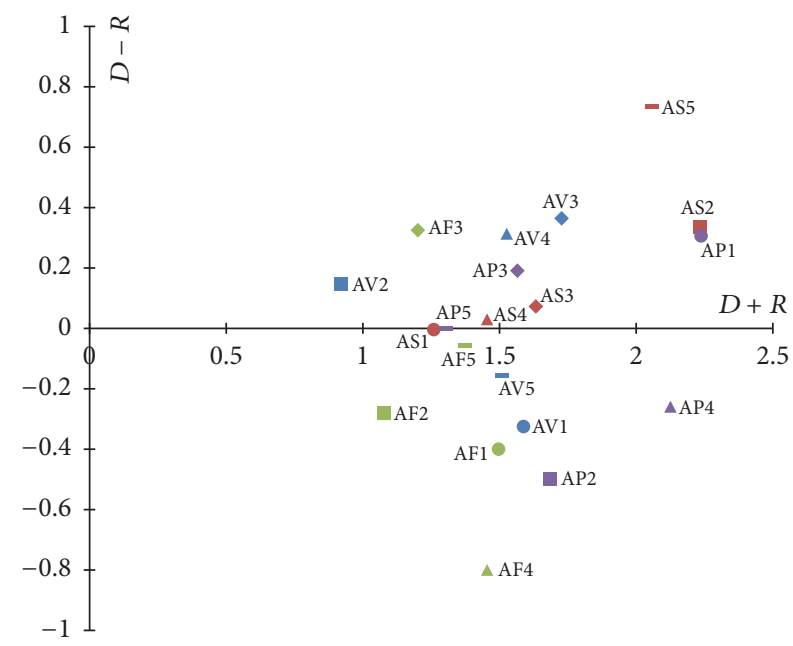

FIGURE 10: Cause-effect relationship diagram for all indicators of energy security (Case 3). 
TABLE 12: The result of Fuzzy-DEMATEL analysis for Accessibility (Case 2).

\begin{tabular}{|c|c|c|c|c|c|c|c|c|c|}
\hline \multirow{2}{*}{ Indicator } & \multirow{2}{*}{$D$} & \multirow{2}{*}{$R$} & \multirow{2}{*}{$D+R$} & \multirow{2}{*}{$D-R$} & \multicolumn{5}{|c|}{ Total-influenced relation matrix } \\
\hline & & & & & AS1 & AS2 & AS3 & AS4 & AS5 \\
\hline Dependency on Middle East oil (AS1) & 0.92 & 1.31 & 2.21 & -0.33 & 0.187 & 0.280 & 0.331 & 0.061 & 0.045 \\
\hline The effort to promote renewable energies (AS2) & 0.68 & 0.96 & 1.64 & -0.23 & 0.286 & 0.102 & 0.106 & 0.116 & 0.056 \\
\hline The effort to promote independently developed energy resources (AS3) & 0.65 & 0.86 & 1.52 & -0.16 & 0.336 & 0.106 & 0.116 & 0.040 & 0.033 \\
\hline Human resources for nuclear energy (AS4) & 0.78 & 0.70 & 1.49 & 0.08 & 0.140 & 0.123 & 0.083 & 0.117 & 0.308 \\
\hline The difficulty in operating nuclear power station (AS5) & 1.39 & 0.60 & 2.01 & 0.72 & 0.373 & 0.339 & 0.211 & 0.346 & 0.134 \\
\hline
\end{tabular}

TABLE 13: The result of Fuzzy-DEMATEL analysis for Affordability (Case 2).

\begin{tabular}{|c|c|c|c|c|c|c|c|c|c|}
\hline \multirow{2}{*}{ Indicator } & \multirow{2}{*}{$D$} & \multirow{2}{*}{$R$} & \multirow{2}{*}{$D+R$} & \multirow{2}{*}{$D-R$} & \multicolumn{5}{|c|}{ Total-influenced relation matrix } \\
\hline & & & & & AF1 & AF2 & AF3 & AF4 & AF5 \\
\hline Fuel cost of electric companies (AF1) & 0.92 & 0.94 & 1.83 & -0.02 & 0.078 & 1.169 & 0.882 & 1.269 & 0.983 \\
\hline Electricity price (AF2) & 0.66 & 0.91 & 1.55 & -0.23 & 0.108 & 0.911 & 0.889 & 0.992 & 1.159 \\
\hline Market price of LNG (AF3) & 1.31 & 0.32 & 1.67 & 0.89 & 0.365 & 1.249 & 0.897 & 1.301 & 1.017 \\
\hline Trade balance (AF4) & 0.35 & 1.34 & 1.72 & -0.90 & 0.059 & 0.884 & 0.865 & 0.920 & 0.966 \\
\hline Economic growth ratio (AF5) & 1.05 & 0.78 & 1.81 & 0.24 & 0.308 & 0.998 & 0.975 & 1.281 & 0.953 \\
\hline
\end{tabular}

TABLE 14: The result of Fuzzy-DEMATEL analysis for Acceptability (Case 2).

\begin{tabular}{lccccccccc}
\hline Indicator & \multirow{2}{*}{$D$} & \multirow{2}{*}{$R$} & $D+R$ & $D-R$ & \multicolumn{4}{c}{ Total-influenced relation matrix } \\
& & & & & AP1 & AP2 & AP3 & AP4 & AP5 \\
\hline Consumption of fossil fuels (AP1) & 1.26 & 0.95 & 2.23 & 0.22 & 0.091 & 0.349 & 0.206 & 0.386 & 0.213 \\
CO2 emission from energy sources (AP2) & 1.12 & 0.81 & 1.94 & 0.21 & 0.094 & 0.065 & 0.231 & 0.422 & 0.275 \\
Radioactive waste (AP3) & 2.21 & 1.99 & 4.18 & 0.17 & 0.377 & 0.169 & 0.414 & 0.669 & 0.596 \\
Supporting ratio for nuclear energy (AP4) & 1.77 & 2.46 & 4.20 & -0.66 & 0.185 & 0.103 & 0.558 & 0.398 & 0.510 \\
Voice and accountability (AP5) & 1.87 & 1.96 & 3.81 & -0.10 & 0.190 & 0.104 & 0.578 & 0.615 & 0.364 \\
\hline
\end{tabular}

TABLE 15: The result of Fuzzy-DEMATEL analysis for all indicators of energy security (Case 3).

\begin{tabular}{|c|c|c|c|c|c|}
\hline Dimension & All indicators & $D$ & $R$ & $D+R$ & $D-R$ \\
\hline \multirow{5}{*}{ Availability } & Self-sufficiency (AV1) & 0.61 & 0.97 & 1.58 & -0.32 \\
\hline & Oil stock (AV2) & 0.54 & 0.37 & 0.92 & 0.15 \\
\hline & Share of renewables in total electricity supply (AV3) & 1.06 & 0.66 & 1.73 & 0.36 \\
\hline & TPES (AV4) & 0.94 & 0.59 & 1.53 & 0.31 \\
\hline & Total installed electricity generation capacity (AV5) & 0.67 & 0.84 & 1.50 & -0.15 \\
\hline \multirow{5}{*}{ Accessibility } & Dependency on Middle East oil (AS1) & 0.63 & 0.63 & 1.26 & 0.00 \\
\hline & The effort to promote renewable energies (AS2) & 1.30 & 0.95 & 2.23 & 0.34 \\
\hline & The effort to promote independently developed energy resources (AS3) & 0.86 & 0.78 & 1.63 & 0.07 \\
\hline & Human resources for nuclear energy (AS4) & 0.74 & 0.72 & 1.46 & 0.03 \\
\hline & The difficulty in operating nuclear power station (AS5) & 1.41 & 0.62 & 2.05 & 0.74 \\
\hline \multirow{5}{*}{ Affordability } & Fuel cost of electric companies (AF1) & 0.52 & 0.97 & 1.49 & -0.40 \\
\hline & Electricity price (AF2) & 0.37 & 0.70 & 1.07 & -0.28 \\
\hline & Market price of LNG (AF3) & 0.78 & 0.41 & 1.20 & 0.33 \\
\hline & Trade balance (AF4) & 0.24 & 1.16 & 1.45 & -0.80 \\
\hline & Economic growth ratio (AF5) & 0.65 & 0.72 & 1.37 & -0.05 \\
\hline \multirow{5}{*}{ Acceptability } & Consumption of fossil fuels (AP1) & 1.29 & 0.97 & 2.23 & 0.31 \\
\hline & $\mathrm{CO} 2$ emission from energy sources (AP2) & 0.56 & 1.11 & 1.68 & -0.50 \\
\hline & Radioactive waste (AP3) & 0.89 & 0.68 & 1.56 & 0.19 \\
\hline & Supporting ratio for nuclear energy (AP4) & 0.93 & 1.21 & 2.13 & -0.26 \\
\hline & Voice and accountability (AP5) & 0.65 & 0.65 & 1.30 & 0.00 \\
\hline
\end{tabular}


Figures 6-9 and Tables 11-14. The results for each dimension are summarized as follows:

(i) Availability (Figure 6 and Table 11): important and influential factors in the Availability dimension are share of renewables in total electricity supply (AV3) and TPES (AV4) belonging to the cause group, which indicates that the most effective strategy for the improvement of the Availability dimension is to promote the introduction of renewable energies while preventing the increase of TPES. The $D-R$ value of self-sufficiency (AV1) is outstandingly low, suggesting that self-sufficiency is the most sensitively influenced by other factors within the Availability dimension and reflects the condition of the Availability dimension in Japan's energy security.

(ii) Accessibility (Table 12 and Figure 7): the most influential factor within the Accessibility dimension is the difficulty in operating nuclear power station (AS5). This suggests that the effort to restart nuclear energy is much more effective than promoting introduction of renewables and independently developed energy sources in order to improve the Accessibility dimension. Although dependency on Middle East oil (AS1) is categorized as an effect factor, its $D+R$ value is the highest; therefore it can be said that this factor is one of priorities the Japanese government should deal with.

(iii) Affordability (Table 13 and Figure 8): the market price of LNG (AF3) is the most influential factor within the Affordability dimension according to its high $D-R$ value. This result suggests that due to the high importdependency of Japan the Affordability dimension of Japan's energy security is highly sensitive to energy prices.

(iv) Acceptability (Table 14 and Figure 9): the radioactive waste (AP3) is both important and influential factor within the Acceptability dimension, which indicates that the most crucial issue for the improvement of Acceptability dimension is to accelerate several approaches to solve the problems concerning radioactive wastes such as final disposal of high level wastes or nuclear fuel cycle. Consumption of fossil fuels (AP1) and CO2 emission from energy sources (AP2) are very influential factors, but their importance values are low within the Acceptability dimension. This result indicates that reduction of fossil fuel consumption and $\mathrm{CO} 2$ emissions currently do not have significant priority for Japan in terms of energy security.

\subsubsection{Structural Analysis of the Indicators of Energy Security} (Case 3). Table 15 and Figure 10 show the result of FuzzyDEMATEL analysis for all indicators of energy security. In this paper, total-influenced relation matrix for all indicators will not be represented for simplicity. The most influential factor in overall energy security is the difficulty in operating nuclear power station (AS5), followed by share of renewables in total electricity supply (AV3) and the effort to promote renewable energies (AS2). Supporting ratio for nuclear energy (AP4) is categorized as an effect group among both acceptability and overall energy security, but in both cases it has a significantly high importance. This result indicates that supporting ratio for nuclear energy, which has priority in Japan's energy policy, may not necessarily contribute to the improvement of energy security. On the whole, the result of Fuzzy-DEMATEL analysis in this study confirms the current energy policy strategy in which nuclear energy and renewable energies play important roles for future energy security in Japan.

On the other hand, the effort to promote renewable energies (AS2) is an effect factor and do not have a high importance among indicators within the Accessibility dimension (Case 2), but it is both an influential and important factor among all indicators of energy security (Case 3). Similarly, the importance of consumption of fossil fuels (AP1) is not high among indicators within the Acceptability dimension (Case 2 ), but it is the highest among all indicators of energy security (Case 3).

These results show that the importance and the influence of the individual factor may vary depending on the focused scale of discussion, that is, within a certain dimension of the energy policy or the energy security as a whole. This implies that the measures to improve a certain dimension of the energy security may not necessarily contribute to the improvement of overall energy security due to tradeoffs among factors composing energy security. As energy security consists of various factors, and they belong to various dimension of energy security and interact with each other in both positive and negative manners, careful considerations are required to establish the policy measures that may lead to improvement of all dimensions of energy security. As mentioned by Sovacool and Saunders [32], complete elimination of the tradeoffs among factors composing energy security is impossible. Therefore it is essential for policymakers to understand that no single policy measure can meet all dimensions of energy security and to establish the policy measure after clarifying the prioritized dimension of energy security of the country. In addition, it is important to design the overall strategy to minimize and manage energy security tradeoffs when establishing the policy measures.

\section{Conclusion}

This study conducted the quantitative analysis of Japan's energy security based on APERC's 4As framework and using fuzzy logic in order to clarify the path Japan should take to maintain and secure its energy security. According to our results, Japan's energy security clearly turned to decline after experiencing Fukushima accident; however, an upward trend after 2012 could be observed due to the change of government's measures to deal with Fukushima accident. In respect to each dimension of $4 \mathrm{As}$, it is found that different dimensions have been affected in different manners. There was no remarkable fluctuation from 2008 to 2013 in the Availability and Accessibility dimensions, whereas the Affordability and Acceptability dimensions were negatively influenced by the 
change of Japan's energy structure resulting from Fukushima accident. This confirms that Fukushima accident had big impacts on Japan in economic, environmental, and social aspects. The structural analysis using the Fuzzy-DEMATEL method shows that the Availability dimension is the most important and influential dimension in energy security, and nuclear energy and renewables are expected to play important roles for future energy security in Japan. These results could be interpreted to energy policy measures such that the reinforcement of Availability dimension and dealing with the problems concerning nuclear energy and renewables would be the optimum pathway to secure and improve future energy security in Japan. Also, as the importance and the influence of the individual factor may vary depending on the focused scale, policymakers should clarify the prioritized dimension of energy security and design a comprehensive energy strategy that may contribute toward minimizing tradeoffs among factors of energy security.

This study presented the nonconventional method for quantitatively evaluating energy security using the fuzzy logic methodology. Although the fuzzy logic is a useful tool for handling the system such as energy security, it should be noted that certain limitations are associated with the methodology itself. The result may depend on the assignment of linguistic values of indicators, which in some cases the assignment has to be done in a subjective manner and thus ambiguity included in subjective assignment of linguistic values cannot be completely eliminated. Therefore care should be taken when assigning linguistic values to indicators. As for the analysis of energy security, we need to utilize available data and information concerning indicators and to qualitatively analyze the overall energy situation which may influence the indicators, including the establishment of relevant institutions and systems, enhancement of regulations, and the government's intent, as thoroughly as possible. The issue is also true for evaluating directinfluenced relationships among factors by using linguistic values in the Fuzzy-DEMATEL analysis. The results of FuzzyDEMATEL analysis should also be carefully interpreted, as the results are for direct influences and magnitudes among factors composing the system and the distinction between positive and negative interactions are not given.

Despite the limitations associated with the use of fuzzy logic discussed above, the methodology presented in this study could be extended with expanded and/or modified indicators composing energy security and be applied to quantitative analysis of energy security in other countries or regions.

\section{Appendix}

\section{Procedures of the Fuzzy-DEMATEL Analysis}

The procedures of the Fuzzy-DEMATEL analysis in this study are identical to those utilized by Ren and Sovacool [13] and Wu and Lee [27] and are summarized hereafter.

Step 1. Transform linguistic values in Tables 5-9 into triangular fuzzy numbers according to Table 4 and set the initial direct-influenced relation matrix $\widetilde{A}$ (this matrix is a $n \times n$ matrix obtained by pairwise companions in terms of influences and directions between factors) based on

$$
\begin{aligned}
& \widetilde{A}=\left[\widetilde{a}_{i j}\right]_{n \times n}=\left[\begin{array}{ccccc}
0 & \tilde{a}_{12} & \cdots & \tilde{a}_{1(n-1)} & \tilde{a}_{1 n} \\
\tilde{a}_{21} & 0 & \cdots & \tilde{a}_{2(n-1)} & \widetilde{a}_{2 n} \\
\vdots & \vdots & \ddots & \vdots & \vdots \\
\vdots & \vdots & \cdots & \ddots & \vdots \\
\widetilde{a}_{n 1} & \widetilde{a}_{n 2} & \cdots & \tilde{a}_{n(n-1)} & 0
\end{array}\right], \\
& \widetilde{a}_{i j}=\left(a_{i j}^{L}, a_{i j}^{M}, a_{i j}^{U}\right),
\end{aligned}
$$

where $\widetilde{a}_{i j}$ is the degree to which the factor $i$ affects the factor $j(i, j=1,2, \ldots, n)$ and $a_{i j}^{L}, a_{i j}^{M}, a_{i j}^{U}$ represent the $x$ coordinates at the left edge, the apex, and the right edge of the triangular fuzzy number, respectively.

Step 2. Calculate the normalized direct-influenced relation matrix $\widetilde{X}$ based on

$$
\begin{aligned}
r & =\max _{1 \leq i \leq n}\left(\sum_{j=1}^{n} a_{i j}^{U}\right), \\
\widetilde{X} & =\left[\widetilde{x}_{i j}\right]_{n \times n}, \\
\tilde{x}_{i j} & =\frac{\widetilde{a}_{i j}}{r}=\left(\frac{a_{i j}^{L}}{r}, \frac{a_{i j}^{M}}{r}, \frac{a_{i j}^{U}}{r}\right) .
\end{aligned}
$$

Step 3. Calculate the total-influenced relation matrix $\widetilde{T}$ shown in (A.3), in which the direct-influenced relation is combined with the indirect-influenced relation, based on (A.4):

$$
\begin{aligned}
\widetilde{T} & =\left[\widetilde{t}_{i j}\right]_{n \times n}=\lim _{w \rightarrow \infty}\left(\widetilde{X}+\widetilde{X}^{2}+\cdots+\widetilde{X}^{w}\right), \\
\widetilde{t}_{i j} & =\left(t_{i j}^{L}, t_{i j}^{M}, t_{i j}^{U}\right), \\
{\left[t_{i j}^{L}\right]_{n \times n} } & =X^{L} \times\left(I-X^{L}\right)^{-1}, \\
{\left[t_{i j}^{M}\right]_{n \times n} } & =X^{M} \times\left(I-X^{M}\right)^{-1}, \\
{\left[t_{i j}^{U}\right]_{n \times n} } & =X^{U} \times\left(I-X^{U}\right)^{-1},
\end{aligned}
$$

where $X^{L}, X^{M}, X^{U}$ represent the normalized directinfluenced relation matrix for the left edge, the apex, and the right edge of the triangular fuzzy number, respectively.

Step 4. Calculate the sum of rows and the sum of columns, which are separately denoted as $D, R$ for the left edge, the apex, and the right edge of the triangular fuzzy number, respectively. Then, obtain the set of $\widetilde{D}_{i}$ and $\widetilde{R}_{j}(i, j=$ 
$1,2, \ldots, n)$, which represents the influence degree and the influenced degree, respectively, based on

$$
\begin{aligned}
& \widetilde{D}_{i}=\sum_{j=1}^{n} \widetilde{t}_{i j}, \\
& \widetilde{R}_{j}=\sum_{i=1}^{n} \widetilde{t}_{i j} .
\end{aligned}
$$

Step 5. Calculate $\widetilde{D}-\widetilde{R}$ and $\widetilde{D}+\widetilde{R}(i, j=1,2, \ldots, n)$, which represents the degree to which the factor influences other factors and the degree of importance which the factor has in the studied system, respectively.

Step 6. Defuzzify the total-influenced relation matrix $\widetilde{T}$, namely, the influence degree $\widetilde{D}$ and the influenced degree $\widetilde{R}$ of each factor, the magnitude of influence $\widetilde{D}-\widetilde{R}$, and the degree of importance $\widetilde{D}+\widetilde{R}$ to obtain the respective crisp values, $D, R, D+R$, and $D-R$.

The CFCS (Converting Fuzzy data into Crisp Scores) method proposed by Opricovic and Tzeng [33] is utilized for defuzzification process in this study. The CFCS method can distinguish between two fuzzy numbers which have the same crisp value but have different shapes and therefore give a better crisp value than the centroid method. The defuzzication process is as follows [27].

Step 1 . Set the fuzzy numbers $\widetilde{b}_{i j}$, which is the degree to which the factor $i$ affects the factor $j(i, j=1,2, \ldots, n)$ based on (A.6). $b_{i j}^{l}, b_{i j}^{m}, b_{i j}^{u}$ represent the $x$-coordinates at the left edge, the apex, and the right edge of the triangular fuzzy number, respectively:

$$
\tilde{b}_{i j}=\left(b_{i j}^{l}, b_{i j}^{m}, b_{i j}^{u}\right)
$$

Then calculate the maximum value of the right edge $u^{\max }$, the minimum value of the left edge $l^{\mathrm{min}}$, and the difference of them $\Delta_{\min }^{\max }$, based on (A.7)-(A.9), respectively:

$$
\begin{aligned}
u^{\max } & =\max b_{i j}^{u}, \\
l^{\min } & =\min b_{i j}^{l}, \\
\Delta_{\min }^{\max } & =u^{\max }-l^{\min } .
\end{aligned}
$$

Step 2. Normalize the triangular fuzzy number based on

$$
\begin{aligned}
x u_{i j} & =\frac{\left(b_{i j}^{u}-l^{\min }\right)}{\Delta_{\min }^{\max }}, \\
x m_{i j} & =\frac{\left(b_{i j}^{m}-l^{\min }\right)}{\Delta_{\min }^{\max }}, \\
x l_{i j} & =\frac{\left(b_{i j}^{l}-l^{\min }\right)}{\Delta_{\min }^{\max }} .
\end{aligned}
$$

Step 3. Calculate the normalized left and right threshold values based on (A.11) and (A.12), respectively, then calculate the total normalized crisp value based on (A.13):

$$
\begin{aligned}
x l s_{i j} & =\frac{x m_{i j}}{\left(1+x m_{i j}-x l_{i j}\right)}, \\
x u s_{i j} & =\frac{x u_{i j}}{\left(1+x u_{i j}-x m_{i j}\right)}, \\
x_{i j} & =\frac{\left[x l s_{i j}\left(1-x l s_{i j}\right)+x u s_{i j} \times x u s_{i j}\right]}{\left[1-x l s_{i j}+x u s_{i j}\right]} .
\end{aligned}
$$

Step 4. Calculate the final crisp value based on

$$
\text { crisp value }=l^{\min }+x_{i j} \times \Delta_{\min }^{\max } \text {. }
$$

\section{Disclosure}

Yoshiyuki Takahashi and Hironobu Unesaki's present address is Kyoto University, Yoshida-honmachi, Sakyo-ku, Kyoto 606-8501, Japan. An earlier version of this work was presented as an abstract at the Annual Meeting of the Atomic Energy Society of Japan, 2017

\section{Conflicts of Interest}

The authors declare that there are no conflicts of interest regarding the publication of this paper.

\section{Acknowledgments}

The authors would like to thank Dr. Jeffrey B. Kucharski and Mr. Shoki Kosai of Graduate School of Energy Science, Kyoto University, for their invaluable comments during the course of this study.

\section{References}

[1] M. Hayashi and L. Hughes, "The Fukushima nuclear accident and its effect on global energy security," Energy Policy, vol. 59, pp. 102-111, 2013.

[2] V. Vivoda, "Japan's energy security predicament postFukushima," Energy Policy, vol. 46, pp. 135-143, 2012.

[3] K. Koyama, "Japan's post-fukushima energy policy challenges," Asian Economic Policy Review, vol. 8, no. 2, pp. 274-293, 2013.

[4] W. Poortinga, M. Aoyagi, and N. F. Pidgeon, "Public perceptions of climate change and energy futures before and after the Fukushima accident: a comparison between Britain and Japan," Energy Policy, vol. 62, pp. 1204-1211, 2013.

[5] L. Chester, "Conceptualising energy security and making explicit its polysemic nature," Energy Policy, vol. 38, no. 2, pp. 887-895, 2010.

[6] B. W. Ang, W. L. Choong, and T. S. Ng, "Energy security: definitions, dimensions and indexes," Renewable \& Sustainable Energy Reviews, vol. 42, pp. 1077-1093, 2015.

[7] B. K. Sovacool, I. Mukherjee, I. M. Drupady, and A. L. D’Agostino, "Evaluating energy security performance from 1990 
to 2010 for eighteen countries," Energy, vol. 36, no. 10, pp. 58465853, 2011.

[8] L. Yao and Y. Chang, "Energy security in China: a quantitative analysis and policy implications," Energy Policy, vol. 67, pp. 595604, 2014.

[9] A. E. Abouelnaga, A. Metwally, M. E. Nagy, and S. Agamy, "Optimum selection of an energy resource using fuzzy logic," Nuclear Engineering and Design, vol. 239, no. 12, pp. 3062-3068, 2009.

[10] D. H. S. Tay, D. K. S. Ng, N. E. Sammons, and M. R. Eden, "Fuzzy optimization approach for the synthesis of a sustainable integrated biorefinery," Industrial \& Engineering Chemistry Research, vol. 50, no. 3, pp. 1652-1665, 2011.

[11] A. H. I. Lee, M.-C. Hung, H.-Y. Kang, and W. L. Pearn, "A wind turbine evaluation model under a multi-criteria decision making environment," Energy Conversion and Management, vol. 64, pp. 289-300, 2012.

[12] L. Suganthi, S. Iniyan, and A. A. Samuel, "Applications of fuzzy logic in renewable energy systems-a review," Renewable \& Sustainable Energy Reviews, vol. 48, pp. 585-607, 2015.

[13] J. Ren and B. K. Sovacool, "Quantifying, measuring, and strategizing energy security: determining the most meaningful dimensions and metrics," Energy, vol. 76, pp. 838-849, 2014.

[14] B. Kruyt, D. P. van Vuuren, H. J. M. de Vries, and H. Groenenberg, "Indicators for energy security," Energy Policy, vol. 37, no. 6, pp. 2166-2181, 2009.

[15] B. K. Sovacool and I. Mukherjee, "Conceptualizing and measuring energy security: a synthesized approach," Energy, vol. 36, no. 8, pp. 5343-5355, 2011.

[16] L. Hughes, “The four 'R's of energy security," Energy Policy, vol. 37, no. 6, pp. 2459-2461, 2009.

[17] D. Kleber, "The U.S. Department of Defense: valuing energy security," Journal of Energy Security, 2009.

[18] A. Cherp and J. Jewell, "The three perspectives on energy security: Intellectual history, disciplinary roots and the potential for integration," Current Opinion in Environmental Sustainability, vol. 3, no. 4, pp. 202-212, 2011.

[19] APERC, A Quest for Energy Security in the 21st Century: Resources and Constraints, Asia Pacific Energy Research Centre, 2007.

[20] A. Cherp and J. Jewell, "The concept of energy security: Beyond the four as," Energy Policy, vol. 75, pp. 415-421, 2014.

[21] The World Bank, "Worldwide governance indicators," 2015, http://info.worldbank.org/governance/wgi/index.aspx\#home.

[22] L. A. Zadeh, "Fuzzy sets," Information and Control, vol. 8, no. 3, pp. 338-353, 1965.

[23] L. A. Zadeh, "Outline of a new approach to the analysis of complex systems and decision processes," IEEE Transactions on Systems, Man, and Cybernetics, vol. 3, no. 1, pp. 28-44, 1973.

[24] J. Li, M.-S. Yim, and D. McNelis, "Assessing the proliferation resistance of nuclear fuel cycle systems using a fuzzy logic-based barrier method," Nuclear Technology, vol.162, no. 3, pp. 293-307, 2008.

[25] S. E. Skutnik and M.-S. Yim, "Assessment of fuel cycle proliferation resistance dynamics using coupled isotopic characterization," Nuclear Engineering and Design, vol. 241, no. 8, pp. 32703282, 2011.

[26] A. Gabus and E. Fontela, "Perceptions of the world problematique: communication procedure, communicating with those bearing collective responsibility," Dematel Report 1, Battelle Geneva Research Centre, Geneva, Switzerland, 1973.
[27] W. W. Wu and Y. T. Lee, "Developing global managers' competencies using the fuzzy DEMATEL method," Expert Systems with Applications, vol. 32, no. 2, pp. 499-507, 2007.

[28] J. Jassbi, F. Mohamadnejad, and H. Nasrollahzadeh, "A fuzzy DEMATEL framework for modeling cause and effect relationships of strategy map," Expert Systems with Applications, vol. 38, no. 5, pp. 5967-5973, 2011.

[29] D. Dalalah, M. Hayajneh, and F. Batieha, "A fuzzy multi-criteria decision making model for supplier selection," Expert Systems with Applications, vol. 38, no. 7, pp. 8384-8391, 2011.

[30] B. Chang, C. Chang, and C. Wu, "Fuzzy DEMATEL method for developing supplier selection criteria," Expert Systems with Applications, vol. 38, no. 3, pp. 1850-1858, 2011.

[31] R. J. Lin, "Using fuzzy DEMATEL to evaluate the green supply chain management practices," Journal of Cleaner Production, vol. 40, pp. 32-39, 2013.

[32] B. K. Sovacool and H. Saunders, "Competing policy packages and the complexity of energy security," Energy, vol. 67, pp. 641651, 2014.

[33] S. Opricovic and G.-H. Tzeng, "Defuzzification within a multicriteria decision model," International Journal of Uncertainty, Fuzziness and Knowledge-Based Systems, vol. 11, no. 5, pp. 635652, 2003. 


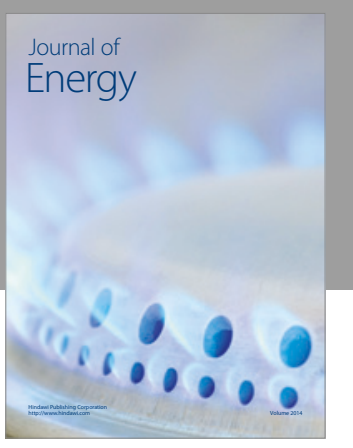

Journal of

Industrial Engineering
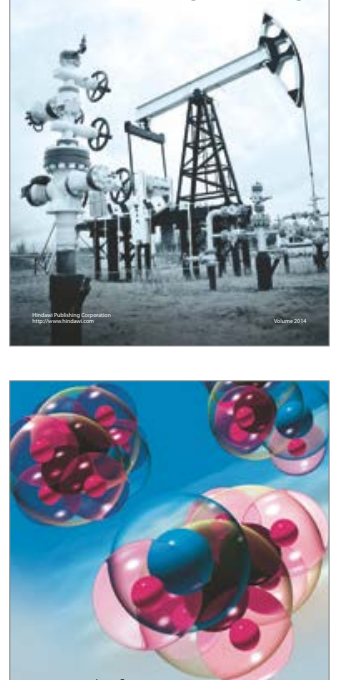

Fuels
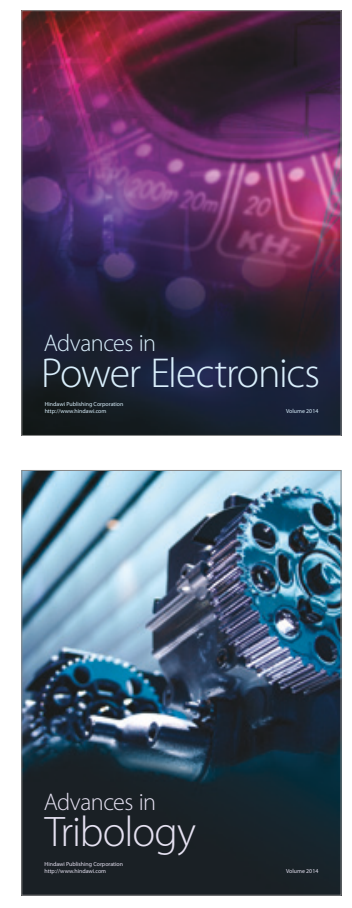
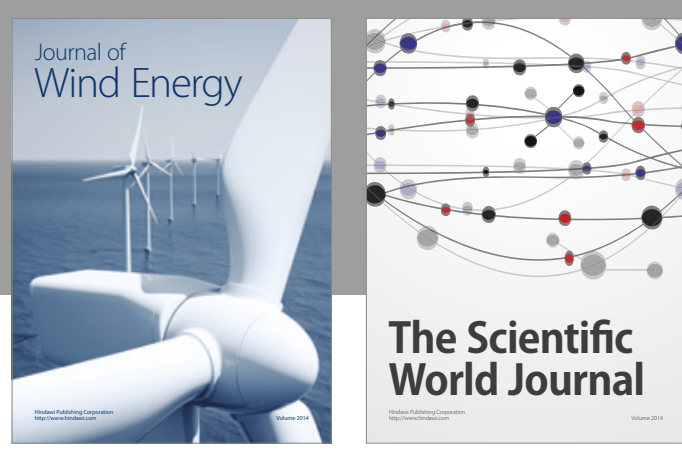

The Scientific World Journal
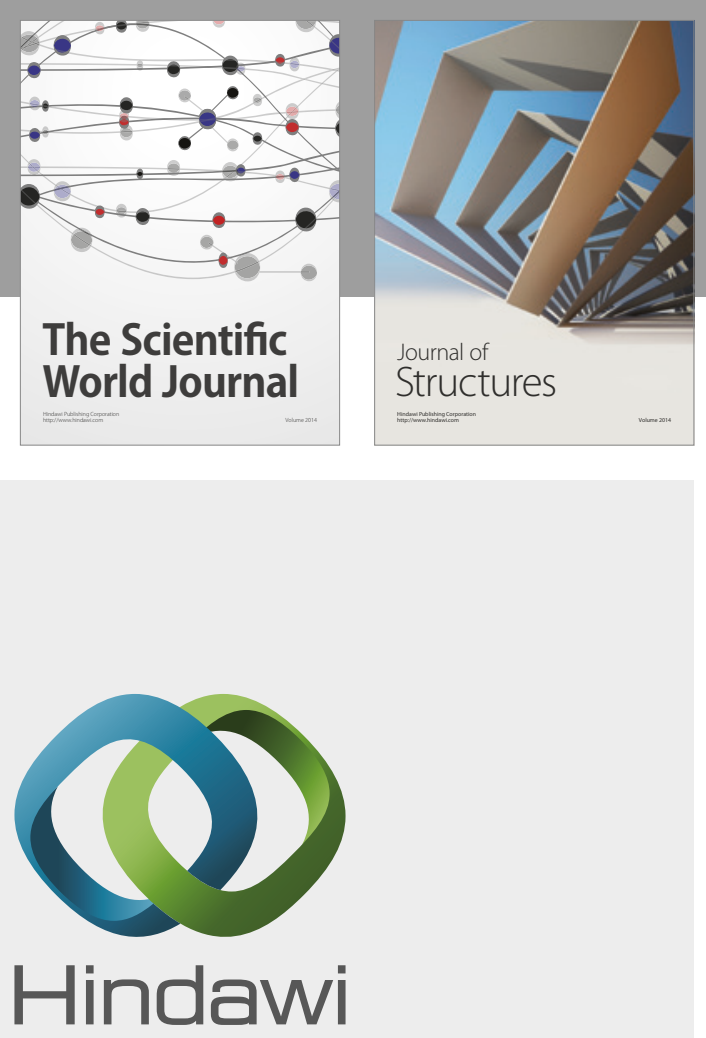

Submit your manuscripts at

https://www.hindawi.com
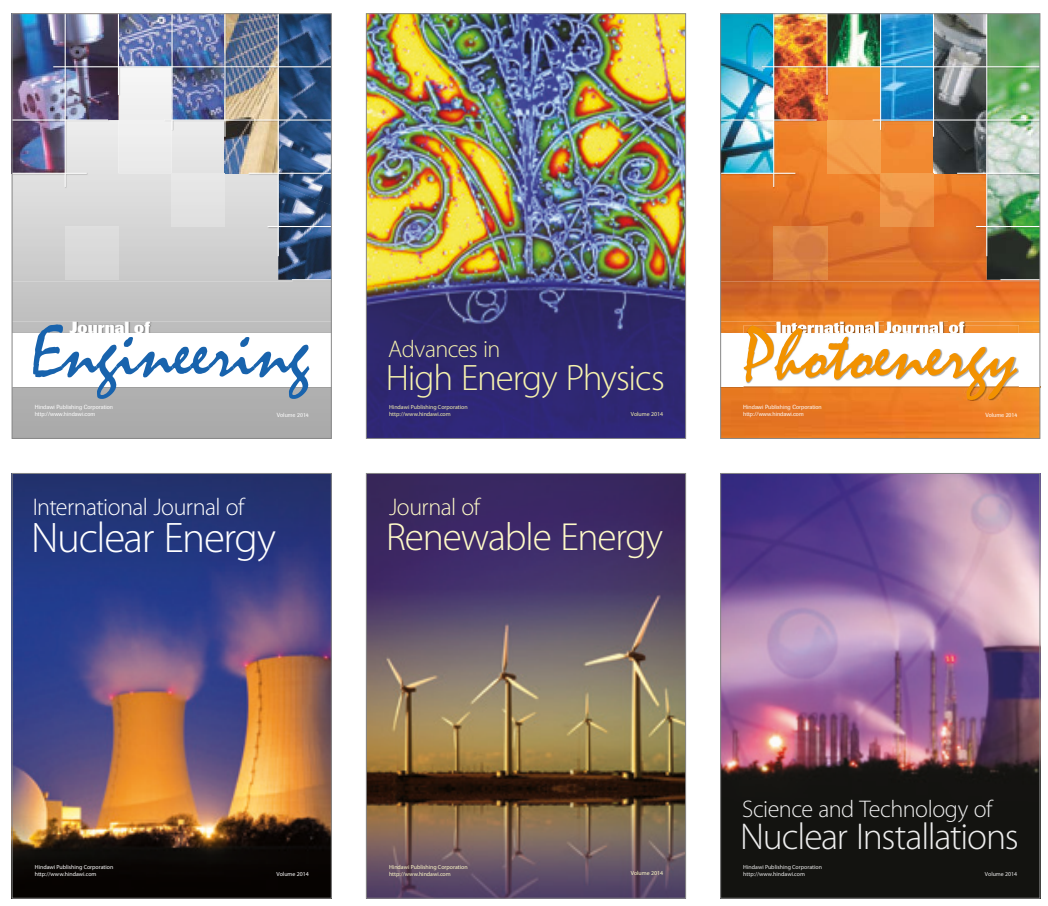

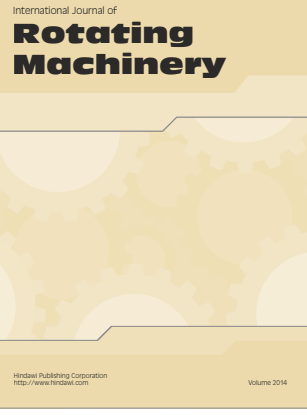

Journal of

Petroleum Engineering

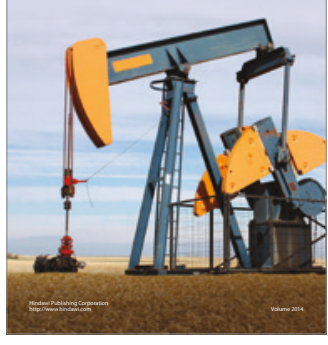

Journal of
Solar Energy
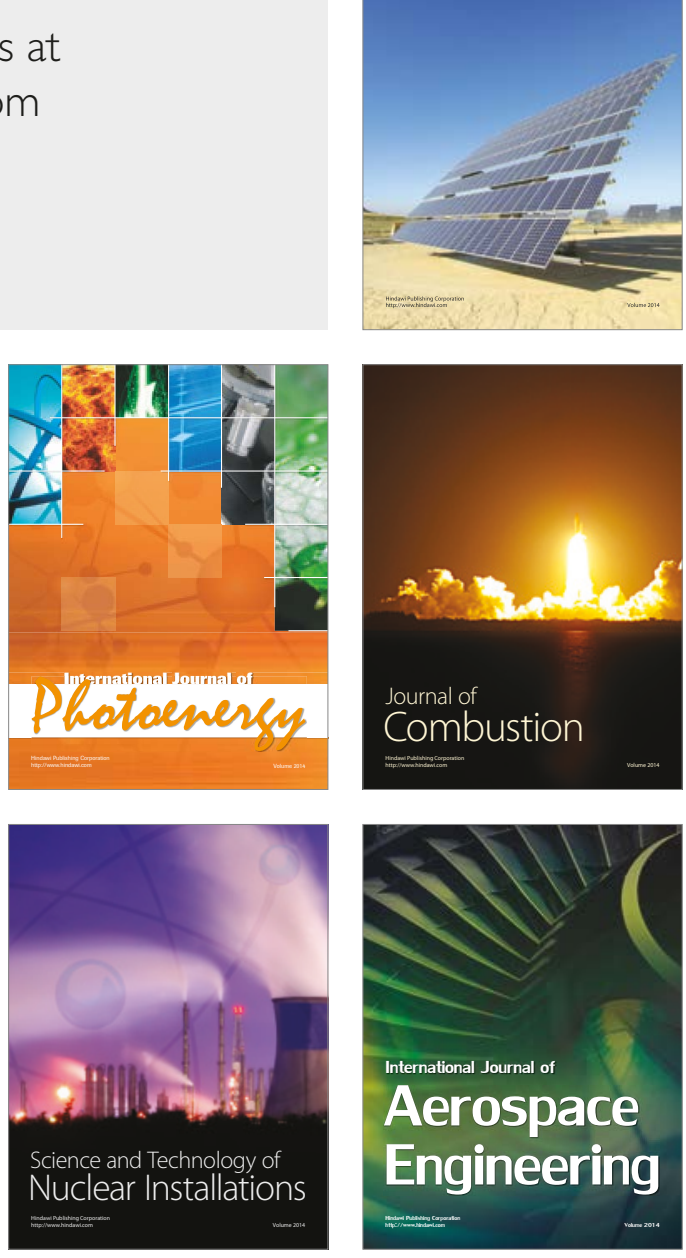